\title{
The effect of socioeconomic status on access to primary care: an audit study
}

\author{
Michelle E. Olah PhD, Gregory Gaisano MSc, Stephen W. Hwang MD MPH
}

\begin{abstract}
Background: Health care office staff and providers may discriminate against people of low socioeconomic status, even in the absence of economic incentives to do so. We sought to determine whether socioeconomic status affects the response a patient receives when seeking a primary care appointment.
\end{abstract}

Methods: In a single unannounced telephone call to a random sample of family physicians and general practices $(n=375)$ in Toronto, Ontario, a male and a female researcher each played the role of a patient seeking a primary care physician. Callers followed a script suggesting either high (i.e., bank employee transferred to the city) or low (i.e., recipient of social assistance) socioeconomic status, and either the presence or absence of chronic health conditions (diabetes and low back pain). We randomized the characteristics of the caller for each office. Our primary outcome was whether the caller was offered an appointment.

Results: The proportion of calls resulting in an appointment being offered was significantly higher when the callers presented themselves as having high socioeconomic status than when they presented as having low socioeconomic status $(22.6 \%$ v. $14.3 \%, p=0.04)$ and when the callers stated the presence of chronic health conditions than when they did not $(23.5 \%$ v. $12.8 \%$, $p=0.008$ ). In a model adjusted for all independent variables significant at a $p$ value of 0.10 or less (presence of chronic health conditions, time since graduation from medical school and membership in the College of Family Physicians of Canada), high socioeconomic status was associated with an odds ratio of 1.78 (95\% confidence interval 1.02-3.08) for the offer of an appointment. Socioeconomic status and chronic health conditions had independent effects on the likelihood of obtaining an appointment.

Interpretation: Within a universal health insurance system in which physician reimbursement is unaffected by patients' socioeconomic status, people presenting themselves as having high socioeconomic status received preferential access to primary care over those presenting themselves as having low socioeconomic status.
A ccess to primary care is vital for good health. ${ }^{1}$ Unfortunately, people of low socioeconomic status encounter many barriers to obtaining health care. ${ }^{2}$ One potential barrier is discrimination by health care providers and office staff, where discrimination is defined as the process by which members of a socially defined group are treated differently owing to their membership in that group. ${ }^{3}$

Discrimination on the basis of socioeconomic status is difficult to distinguish from behaviour driven by economic incentives when there is a strong association between socioeconomic status and extent of health insurance coverage. Thus, the ideal setting for a study of discrimination is one in which physicians receive the same reimbursement regardless of a patient's socioeconomic status. This situation prevails in Ontario, where all residents of the province are covered by a single public insurer, copayments by pa- tients are not permitted, and there are no deductibles for physician visits. ${ }^{4}$

We sought to determine whether socioeconomic status and the presence or absence of chronic health conditions affect the response a person receives when calling physicians' offices seeking a primary care appointment. Our main hypothesis was that people of high socioeconomic status would be more likely to be offered an appointment for primary care than people of low socioeconomic status.

\section{Methods}

\section{Design}

We used a randomized controlled audit study design in which we made unannounced telephone calls to the offices of a random sample of primary care physicians in Toronto, Ontario. Callers followed a standardized script and presented them-
Competing interests: None declared.

This article has been peer reviewed.

Correspondence to:

Stephen Hwang,

hwangs@smh.ca

CMAJ 2013. DOI:10.1503 /cmaj.121383 
selves as a person asking to be seen as a new primary care patient (Table 1). We contacted each office once, with randomization to 1 of 4 patient scenarios using a $2 \times 2$ design: high socioeconomic status (i.e., a bank employee transferred to the city) versus low socioeconomic status (i.e., receiving social assistance), and chronic health conditions (diabetes and back pain) versus no chronic health conditions. We used a random number generator for randomization. Our primary outcome was whether the caller received an unconditional offer of an appointment.

\section{Participants}

In Canada, family physicians and general practitioners are the main providers of primary care. We used the College of Physicians and Surgeons of Ontario's public database of all licensed physicians in Ontario to identify family physicians and general practitioners in active practice in Toronto as of December 2010 (www.cpso.on .ca/docsearch/). We selected a random sample of about $30 \%$ of these physicians and obtained the following data for each: name, sex, office telephone number, address of primary practice, medical school and year of graduation, membership in the College of Family Physicians of Canada and any practice restrictions. Census data from 2006 were used to determine the median household income tertile of the neighbourhood in which each primary practice was located. ${ }^{5}$

We excluded physicians' offices for the following reasons: the primary practice address or telephone number was not listed in the database; the primary practice address was not in Toronto; the primary practice address was a hospital emergency department, an institution that pro- vides health care only to a specifically defined population (e.g., a nursing home or student health centre) or an organization that does not provide primary care (e.g., an insurance company); physicians designated as residents or fellows in training; physicians whose medical licenses were restricted due to disciplinary action; physicians with practices limited to a specific clinical focus with no provision of primary care (e.g., hospital medicine, sports medicine, travel medicine, addiction medicine, weight loss, reproductive health care, sexual health, HIV care, oncology, geriatrics, palliative care); and physicians operating exclusively "walk-in" practices, where no appointments were given to patients. If 2 or more selected physicians shared the same office telephone number, we randomly selected 1 physician to be contacted and excluded the other physicians at that office.

\section{Audit procedure}

Two researchers, 1 male and 1 female, placed the telephone calls. We randomly assigned the sex of the caller for each physician's office. The callers were trained to deliver each patient scenario in a similar manner using a neutral tone of voice. We provided standardized answers to be given in response to questions from the physician's office (Appendix 1, available at www.cmaj.ca/lookup /suppl/doi:10.1503/cmaj.121383/-/DC1).

The researchers called the physicians' offices from March 2011 to July 2011 using dedicated cell phones. We made at least 5 attempts to contact each office. We excluded physicians if information obtained during the call suggested that the physician's practice had been permanently closed or that the physician met one of the exclusion criteria.

\begin{tabular}{|c|c|}
\hline Patient scenario & Script \\
\hline Initial inquiry (all scenarios) & $\begin{array}{l}\text { Hello? Is this } \mathrm{Dr} \text {. } \\
\text { by the person answering the telephone] }\end{array}$ \\
\hline $\begin{array}{l}\text { High socioeconomic status, no chronic } \\
\text { health conditions }\end{array}$ & $\begin{array}{l}\text { Hi. I was just transferred to Toronto with [name of major } \\
\text { bank], and I need a family doctor for annual check-ups. } \\
\text { Is Dr.___ accepting new patients? }\end{array}$ \\
\hline $\begin{array}{l}\text { High socioeconomic status, with chronic } \\
\text { health conditions }\end{array}$ & $\begin{array}{l}\text { Hi. I was just transferred to Toronto with [name of major } \\
\text { bank], and I need a family doctor for my diabetes and back } \\
\text { problems. } \\
\text { Is Dr. }\end{array}$ \\
\hline $\begin{array}{l}\text { Low socioeconomic status, no chronic } \\
\text { health conditions }\end{array}$ & $\begin{array}{l}\text { Hi. I'm calling 'cause my welfare worker told me that I need } \\
\text { a family doctor for annual check-ups. } \\
\text { Is Dr. __ accepting new patients? }\end{array}$ \\
\hline $\begin{array}{l}\text { Low socioeconomic status, with chronic } \\
\text { health conditions }\end{array}$ & $\begin{array}{l}\text { Hi. I'm calling 'cause my welfare worker told me that I need } \\
\text { a family doctor for my diabetes and back problems. } \\
\text { Is Dr. ___ accepting new patients? }\end{array}$ \\
\hline
\end{tabular}


If an appointment was given, the researcher called back the following day to cancel the appointment.

\section{Outcomes}

Our primary outcome was whether the caller received an unconditional offer of an appointment. We coded responses as follows: an unconditional offer of an appointment to be seen for primary care; an offer of an appointment for an initial screening visit with a physician to determine whether the patient would be accepted for primary care; an offer to be placed on a waiting list for prospective new patients; or a refusal (most often for the stated reason that the physician was not currently accepting new patients). Offers of an initial screening visit or a place on a waiting list were considered to be intermediate outcomes, because they create additional opportunities for patient selection but are not equivalent to an outright refusal. ${ }^{6,7}$ We therefore performed 2 analyses - an analysis using the primary outcome (an unconditional offer of an appointment) and an analysis using a secondary outcome (an unconditional offer of an appointment, an offer of an initial screening visit or a place on a waiting list).

\section{Statistical analysis}

We estimated a priori that $20 \%$ of calls would result in the offer of an appointment and that a
$10 \%$ absolute difference between groups would be clinically meaningful. To achieve power of 0.80 with an $\alpha$ level of 0.05 , our target sample size was 270 in each of the socioeconomic status groups.

We used $\chi^{2}$ tests to compare the characteristics of physicians randomized to different patient scenarios and the proportion of calls that resulted in an appointment in different patient scenarios. We used the Breslow-Day test to determine whether there was heterogeneity in the association between patient socioeconomic status and outcomes among physicians with the characteristics shown in Table 2.

We constructed a logistic regression model in which the dependent variable was the outcome of the request for an appointment and the independent variables were the patient's socioeconomic status and presence or absence of chronic health conditions. We then introduced an interaction term to test for an interaction between socioeconomic status and chronic health conditions. In addition, we constructed logistic regression models in which the dependent variable was the outcome of the request for an appointment and the independent variables were all available characteristics of the patient and physician. We calculated adjusted odds ratios (ORs) in multivariate models that included all independent variables that were significant in univariate analyses at a $p$ value of 0.10 or less.

Table 2: Characteristics of the physicians contacted during the study, by randomization group

\begin{tabular}{|c|c|c|c|c|c|c|}
\hline Characteristic & \multicolumn{6}{|c|}{ Randomization group, no. (\%) } \\
\hline Female sex & $71(38.2)$ & $90(47.6)$ & 0.07 & $68(38.0)$ & $93(47.4)$ & 0.07 \\
\hline $\begin{array}{l}\text { Time since graduation from } \\
\text { medical school, yr }\end{array}$ & & & 0.4 & & & 0.9 \\
\hline $1-10$ & $20(10.8)$ & $16(8.5)$ & & $16(8.9)$ & $20(10.2)$ & \\
\hline $11-20$ & $26(14.0)$ & $35(18.5)$ & & $28(15.6)$ & $33(16.8)$ & \\
\hline$\geq 21$ & $140(75.3)$ & $138(73.0)$ & & $135(75.4)$ & $143(73.0)$ & \\
\hline Low & $57(30.6)$ & $59(31.2)$ & & $58(32.4)$ & $58(29.6)$ & \\
\hline Middle & $78(41.9)$ & $60(31.7)$ & & $59(33.0)$ & $79(40.3)$ & \\
\hline High & $51(27.4)$ & $70(37.0)$ & & $62(34.6)$ & $59(30.1)$ & \\
\hline
\end{tabular}




\section{Ethical review}

This study was approved by the Research Ethics Board of St. Michael's Hospital with some considerations. First, there was no appreciable risk to participants, and the burden of participation in the study was minimal. Second, although the study involved a minor deception and was conducted without the informed consent of participants, our approach was justified owing to the lack of risk to participants and because informed consent would likely alter the behaviour of participants in a way that would render our results invalid. Third, after we completed the collection of the data, we sent a disclosure letter to all physicians whose offices had been randomized to receive a call. Finally, we have taken measures to protect the identity of the physicians, and our study design precluded the possibility of identifying discriminatory practices by any specific physician's office.

\section{Results}

We identified 3367 family physicians and general practitioners in active practice in Toronto in the database. We selected a random sample of 985 physicians, of whom 568 were eligible for the study and randomized to 1 of 4 patient scenarios (Figure 1). We were unable to contact

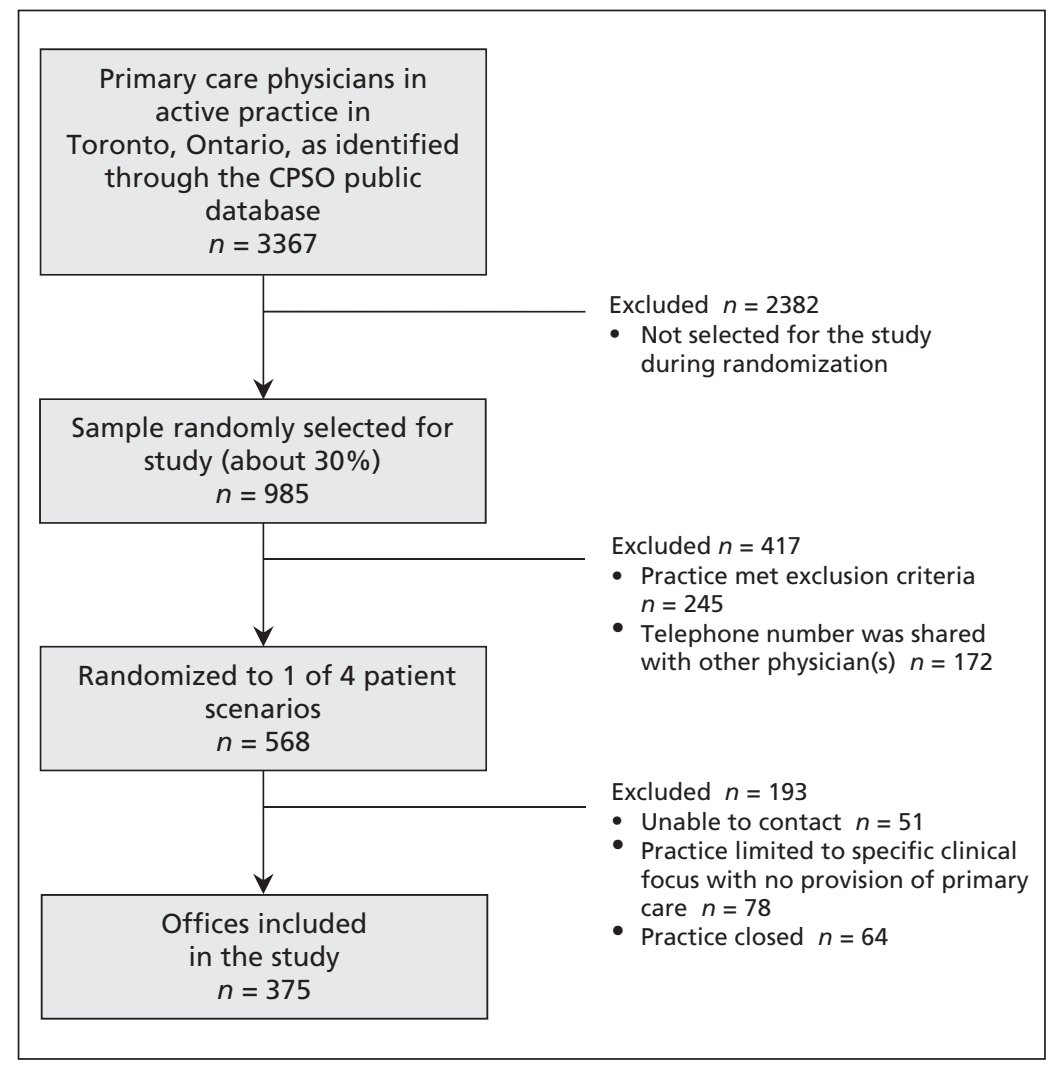

Figure 1: Selection of physicians for the audit. CPSO = College of Physicians and Surgeons of Ontario. anyone at 51 of these offices (9\%), and we found 142 offices $(25 \%)$ to be ineligible for the study at the time of the call because they were either permanently closed $(n=64)$ or had a limited scope of practice, with no provision of primary care $(n=78)$.

Our analyses include outcome data from 375 offices. Most of the responses we obtained were from secretaries and administrative assistants (data not shown). There were no significant differences in the characteristics of the physicians at these offices by randomization group (Table 2).

Overall, 69 (18.4\%) requests resulted in an appointment being offered, 33 (8.8\%) resulted in an offer for a screening visit and $12(3.2 \%)$ resulted in an offer to be placed on a waiting list. A caller with high socioeconomic status was significantly more likely than a caller with low socioeconomic status to be offered an appointment $(22.6 \%$ v. $14.3 \%, p=0.04)$, or to be offered an appointment, screening visit or place on a waiting list $(37.1 \%$ v. $23.8 \%, p=0.005)$ (Table 3). We saw no evidence of heterogeneity in this association related to any physician characteristic. A caller with chronic health conditions was significantly more likely than a caller with no such conditions to be offered an appointment $(23.5 \%$ v. $12.8 \%, p=0.008)$ (Table 3$)$. Socioeconomic status and the presence of chronic health conditions had independent effects on the likelihood of obtaining an appointment, and there was no evidence of a significant interaction effect between these 2 factors. The sex of the caller had no effect on the probability of being offered an appointment.

In an adjusted model accounting for patient and physician characteristics (Table 4), high socioeconomic status was associated with the offer of an appointment (OR 1.78 [95\% confidence interval (CI) 1.02-3.08]) and with the offer of an appointment, screening visit or place on a waiting list (OR 1.93 [95\% CI 1.21-3.11]). The presence of chronic health conditions was also associated with an offer of an appointment (OR 2.10 [95\% CI 1.20-3.68]) and with an offer of an appointment, screening visit or a place on a waiting list (OR 1.45 [95\% CI 0.91-2.32]) (Table 4).

\section{Interpretation}

A person calling a physician's office and asking to be seen as a new primary care patient was more than $50 \%$ more likely to be given an appointment if he or she presented as being of high socioeconomic status. Because we see this finding in a single-payer universal health insur- 
ance system, it provides evidence of discrimination by physicians' offices on the basis of socioeconomic status. The effect of socioeconomic status was independent of the presence or absence of chronic health conditions.

Although our study was not designed to identify why individuals of low socioeconomic status were less likely to receive appointments for primary care than their higher status counterparts, staff at physicians' offices may hold negative attitudes toward this group, especially toward people receiving social assistance. Physicians have been shown to perceive patients with low socioeconomic status more negatively in terms of their personalities, abilities, behavioural tendencies and role demands. ${ }^{8}$ Most previous studies of discrimination in health care have examined the effects of patient race or ethnic background on treatment decisions. ${ }^{9}, 10$ These studies have typically presented physicians with clinical vignettes ${ }^{11,12}$ or used observational databases and adjusted for confounding factors. ${ }^{13} \mathrm{Far}$ fewer studies have focused on discrimination on the basis of patient socioeconomic status. ${ }^{8,14}$ Audit studies, a well-established method of test- ing for discrimination in labour and housing markets, ${ }^{15-17}$ have been used in the United States to show that Medicaid recipients and patients who are uninsured encounter substantial barriers to care. ${ }^{18-21}$ However, these effects may be due to the economic incentive of differing levels of reimbursement, rather than discrimination on the basis of socioeconomic status itself.

Financial barriers to accessing primary care are greatly reduced within Canada's system of universal health insurance. ${ }^{22}$ However, $15 \%$ of Canadians report that they do not have a regular medical doctor. Among those patients who have looked for a doctor unsuccessfully, the most common reason given for not having a doctor is that local physicians are not accepting new patients. ${ }^{23}$ During the past decade, the province of Ontario has encouraged primary care providers to shift from a fee-for-service model to a capitated system in which payments are adjusted for age and sex but not patient comorbidities. ${ }^{24,25}$ This situation creates a possible financial incentive to preferentially enrol patients with few or no chronic health conditions. We found no evidence of such selection; on the contrary, a strong trend in the

Table 3: Outcome of telephone call, by patient characteristic

\begin{tabular}{|c|c|c|c|c|c|}
\hline \multirow[b]{3}{*}{ Characteristic } & \multirow{3}{*}{$\begin{array}{l}\text { No. of } \\
\text { physician } \\
\text { offices } \\
\text { contacted }\end{array}$} & \multicolumn{4}{|c|}{ Outcome } \\
\hline & & \multicolumn{2}{|c|}{$\begin{array}{l}\text { Offered an } \\
\text { appointment }\end{array}$} & \multicolumn{2}{|c|}{$\begin{array}{l}\text { Offered an appointment, } \\
\text { screening visit or place on a } \\
\text { waiting list }\end{array}$} \\
\hline & & No. (\%) & $p$ value* & No. $(\%)$ & $p$ value* \\
\hline Overall & 375 & 69 (18.4) & NA & $114(30.4)$ & NA \\
\hline SES & & & 0.04 & & 0.005 \\
\hline High & 186 & $42(22.6)$ & & $69(37.1)$ & \\
\hline Low & 189 & $27(14.3)$ & & $45(23.8)$ & \\
\hline Chronic health conditions & & & 0.008 & & 0.10 \\
\hline No & 179 & $23(12.8)$ & & $47(26.3)$ & \\
\hline Yes & 196 & $46(23.5)$ & & $67(34.2)$ & \\
\hline Combined scenario & & & 0.009 & & 0.01 \\
\hline $\begin{array}{l}\text { High SES, no chronic health } \\
\text { conditions }\end{array}$ & 88 & $14(15.9)$ & & $30(34.1)$ & \\
\hline $\begin{array}{l}\text { High SES, with chronic } \\
\text { health conditions }\end{array}$ & 98 & $28(28.6)$ & & $39(39.8)$ & \\
\hline $\begin{array}{l}\text { Low SES, no chronic health } \\
\text { conditions }\end{array}$ & 91 & $9 \quad(9.9)$ & & $17(18.7)$ & \\
\hline $\begin{array}{l}\text { Low SES, with chronic } \\
\text { health conditions }\end{array}$ & 98 & $18(18.4)$ & & $28(28.6)$ & \\
\hline Sex & & & 0.8 & & 0.9 \\
\hline Male & 212 & 40 (18.9) & & $65(30.7)$ & \\
\hline Female & 163 & $29(17.8)$ & & $49(30.1)$ & \\
\hline
\end{tabular}


opposite direction was found, with physicians' offices giving preferential access to patients with chronic health problems. This finding suggests that patients with greater medical needs are being appropriately prioritized.

\section{Limitations}

We examined the behaviour of staff at physicians' offices, which does not necessarily reflect the attitudes or directives of the physicians; nonetheless, any discriminatory behaviour by office staff can clearly have an adverse effect on patients' access to physicians.

Referring to having a welfare worker was chosen as one of the few plausible and effective ways for the caller to rapidly convey low socioeconomic status. As a result, our study cannot distinguish between discrimination on the basis of low socioeconomic status and discrimination directed specifically against recipients of social assistance. Furthermore, we could not account for further patient selection that may take place at an initial screening visit or when patients are chosen from a waiting list. In addition, we did not have access to information on the reimbursement model (feefor-service, capitation or blended) under which the physicians were practising.

We chose not to use a study design in which each physician's office received paired calls from callers of high and low socioeconomic status. Although such a design would have had greater power to detect discrimination, the calls would have to have been separated in time to reduce the risk of detection. Our results might then have been influenced by the intermittent opening and closing of physicians' practices to new patients, a phenomenon that is common in the geographic area in which we conducted this study.

Finally, our results may not be generalizable to jurisdictions in which there is a plentiful supply of primary care physicians who are accepting new patients.

\section{Conclusion}

This study provides evidence that discrimination against patients of low socioeconomic status can

\begin{tabular}{|c|c|c|c|c|}
\hline \multirow[b]{3}{*}{ Independent variables } & \multicolumn{4}{|c|}{ Outcome } \\
\hline & \multicolumn{2}{|c|}{ Offered an appointment } & \multicolumn{2}{|c|}{$\begin{array}{l}\text { Offered an appointment, screening visit } \\
\text { or place on a waiting list }\end{array}$} \\
\hline & $\begin{array}{l}\text { Unadjusted OR } \\
\qquad(95 \% \mathrm{Cl})\end{array}$ & $\begin{array}{l}\text { Adjusted OR* } \\
\qquad(95 \% \mathrm{Cl})\end{array}$ & $\begin{array}{l}\text { Unadjusted OR } \\
\qquad(95 \% \mathrm{Cl})\end{array}$ & $\begin{array}{l}\text { Adjusted OR* } \\
\quad(95 \% \mathrm{Cl})\end{array}$ \\
\hline \multicolumn{5}{|l|}{ Patient characteristic } \\
\hline High SES & $1.75(1.03-2.98)$ & $1.78(1.02-3.08)$ & $1.89(1.21-2.95)$ & $1.93(1.21-3.11)$ \\
\hline Chronic health conditions & $2.08(1.20-3.60)$ & $2.10(1.20-3.68)$ & $1.46(0.94-2.28)$ & $1.45(0.91-2.32)$ \\
\hline Female sex & $0.93(0.55-1.58)$ & & $0.97(0.62-1.52)$ & \\
\hline \multicolumn{5}{|l|}{ Physician characteristic } \\
\hline Female sex & $1.28(0.76-2.15)$ & & $1.51(0.97-2.35)$ & $1.12(0.68-1.83)$ \\
\hline $\begin{array}{l}\text { Graduate of LCME-accredited } \\
\text { medical school }\end{array}$ & $1.04(0.59-1.82)$ & & $1.13(0.70-1.81)$ & \\
\hline \multicolumn{5}{|l|}{$\begin{array}{l}\text { Time since graduation from } \\
\text { medical school graduation, yr }\end{array}$} \\
\hline $1-10$ & 1.00 (ref) & 1.00 (ref) & 1.00 (ref) & 1.00 (ref) \\
\hline $11-20$ & $0.74(0.30-1.86)$ & $0.84(0.33-2.15)$ & $0.30(0.13-0.70)$ & $0.34(0.14-0.81)$ \\
\hline$\geq 21$ & $0.42(0.19-0.91)$ & $0.66(0.28-1.54)$ & $0.19(0.09-0.40)$ & $0.29(0.13-0.64)$ \\
\hline $\begin{array}{l}\text { Member of the College of } \\
\text { Family Physicians of Canada }\end{array}$ & $2.63(1.48-4.67)$ & $2.29(1.20-4.40)$ & $2.64(1.65-4.22)$ & $1.96(1.13-3.40)$ \\
\hline \multicolumn{5}{|l|}{$\begin{array}{l}\text { Median income tertile of } \\
\text { neighborhood where primary } \\
\text { practice is located }\end{array}$} \\
\hline Low & 1.00 (ref) & & 1.00 (ref) & \\
\hline Medium & $1.05(0.55-1.99)$ & & $0.98(0.57-1.68)$ & \\
\hline High & $1.01(0.52-1.95)$ & & $1.06(0.61-1.84)$ & \\
\hline
\end{tabular}


occur within a universal health insurance system and have an adverse effect on access to primary health care. Although it is reassuring that patients with chronic health conditions received prioritized access to primary care, our results suggest a need for greater efforts to ensure that physicians and their office staff do not discriminate against people of low socioeconomic status. Further research is needed to determine whether discrimination on the basis of socioeconomic status has an effect on other aspects of health care, such as quality of care and patient-physician communication.

\section{References}

1. Starfield B, Shi L, Macinko J. Contribution of primary care to health systems and health. Milbank $Q$ 2005;83:457-502.

2. Gelberg L, Andersen RM, Leake BD. The behavioral model for vulnerable populations: application to medical care use and outcomes for homeless people. Health Serv Res 2000;34:1273-302.

3. Trivedi AN, Ayanian JZ. Perceived discrimination and use of preventive health services. J Gen Intern Med 2006;21:553-8.

4. Detsky AS, Naylor CD. Canada's health care system — reform delayed. N Engl J Med 2003;349:804-10.

5. Glazier RH, Booth GL, Gozdyra P, et al., editors. Neighbourhood environments and resources for healthy living - a focus on diabetes in Toronto: ICES Atlas. Toronto (ON): Institute for Clinical Evaluative Sciences; 2007.

6. Kirkwood K. Casting call: the perils of auditioning patients. Can Fam Physician 2008;54:831-2.

7. Chafe R, Laupacis A, Levinson W. Accepting new patients: What does the public think about Ontario's policy? Can Fam Physician 2011;57:e68-73.

8. van Ryn M, Burke J. The effect of patient race and socioeconomic status on physicians' perceptions of patients. Soc Sci Med 2000; 50:813-28.

9. Smedley BD, Stith AY, Nelson AR, editors. Unequal treatment: confronting racial and ethnic disparities in health care. Washington (DC): The National Academies Press; 2003.

10. Shavers VL, Fagan P, Jones D, et al. The state of research on racial/ethnic discrimination in the receipt of health care. Am J Public Health 2012;102:953-66.

11. Schulman KA, Berlin JA, Harless W, et al. The effect of race and sex on physicians' recommendations for cardiac catherization. N Engl J Med 1999;340:618-26.

12. Haider AH, Sexton J, Sriram N, et al. Association of unconscious race and social class bias with vignette-based clinical assessments by medical students. JAMA 2011;306:942-51.

13. van Ryn M, Burgess D, Malat J, et al. Physicians' perceptions of patients' social and behavioral characteristics and race disparities in treatment recommendations for men with coronary artery disease. Am J Public Health 2006;96:351-7.

14. Scott A, Shiell A, King M. Is general practitioner decision making associated with patient socioeconomic status? Soc Sci Med 1996; 42:35-46.
15. Riach PA, Rich J. Field experiments of discrimination in the market place. Econ J 2002;112:F480-518.

16. Bertrand M, Mullainathan S. Are Emily and Greg more employable than Lakisha and Jamal? A field experiment on labor market discrimination. Am Econ Rev 2004;94:991-1013.

17. Riach PA, Rich J. Deceptive field experiments of discrimination: Are they ethical? Kyklos 2004;57:457-70.

18. The Medicaid Access Study Group. Access of Medicaid recipients to outpatient care. N Engl J Med 1994;330:1426-30.

19. Asplin BR, Rhodes KV, Levy H, et al. Insurance status and access to urgent ambulatory care follow-up appointments. JAMA 2005;294:1248-54.

20. Bisgaier J, Rhodes KV. Auditing access to specialty care for children with public insurance. N Engl J Med 2011;364:2324-33.

21. Rhodes K. Taking the mystery out of "mystery shopper" studies. N Engl J Med 2011;365:484-6.

22. Schoen C, Doty MM. Inequities in access to medical care in five countries: findings from the 2001 Commonwealth Fund International Health Policy Survey. Health Policy 2004;67:309-22.

23. Access to a regular medical doctor, 2010. Ottawa (ON): Statistics Canada; 2010. Available: www.statcan.gc.ca/pub/82-625-x /2011001/article/11456-eng.htm. (accessed 2011 Aug. 22).

24. Glazier RH, Redelmeier DA. Building the patient-centered medical home in Ontario. JAMA 2010;303:2186-7.

25. Glazier RH, Klein-Geltink J, Kopp A, et al. Capitation and enhanced fee-for-service models for primary care reform: a population-based evaluation. CMAJ 2009;180:E72-81.

Affiliations: From the Centre for Research on Inner City Health (Olah, Gaisano, Hwang), the Keenan Research Centre at the Li Ka Shing Knowledge Institute, St. Michael's Hospital, Toronto, Ont.; and the Division of General Internal Medicine, Department of Medicine (Hwang), University of Toronto, Toronto, Ont.

Contributors: Gregory Gaisano and Michelle Olah contributed equally to this work. All of the authors made substantial contributions to the conception and design of the study, the collection and interpretation of the data, and the writing and revising of the manuscript for important intellectual content. All of the authors approved the final version submitted for publication.

Acknowledgements: The authors thank Marisa Creatore and Peter Gozdyra for providing neighbourhood income data; Jonathan K.B. Hwang for assistance with the preparation of patient scripts and with data entry; and the faculty and staff of the Determinants of Community Health 2 Course, Faculty of Medicine, University of Toronto, for their assistance. The Centre for Research on Inner City Health gratefully acknowledges the support of the Ontario Ministry of Health and Long-Term Care. The views expressed in this publication are the views of the authors and do not necessarily reflect the views of the Ontario Ministry of Health and Long-Term Care or any of the above named organizations or individuals. 